\title{
The risk of paraplegia through medical treatment
}

\author{
T Bacher ${ }^{1}$, M Schiltenwolf ${ }^{2}$, FU Niethard ${ }^{3}$ and V Paeslack ${ }^{4}$ \\ ${ }^{1}$ Sporthilfe e.V. Krankenhaus für Sportverletzte Hellersen, Lüdenscheid; ${ }^{2}$ Stiftung Orthopädische Universitätsklinik \\ Heidelberg, Heidelberg; ${ }^{3}$ Orthopädische Klinik der Medizinischen Fakultät der Rhein-Westf. Technischen Hochschule \\ (RWTH) Aachen, Aachen; ${ }^{4}$ Stiftung Orthopädische Universitätsklinik Heidelberg, Heidelberg, Germany
}

In the Orthopedic University Hospital of Heidelberg (section Orthopedics II, treatment and rehabilitation of paraplegics), 21 patients with iatrogenic paraplegia were treated between 1968 and 1991. Paraplegia occurred in nine cases after procedures close to the spinal cord. In 12 cases paraplegia complicated medical treatment. Procedures close to the spinal cord, such as laminectomy, vertebrotomy, spondylodesis, and peridural anaesthesia, involve the risk of mechanical damage to the spinal cord, the level of paraplegia depends on the area of treatment. Any previous damage to the spinal cord increases the risk of paraplegic complications. The main risks in procedures distant from the spinal cord, such as vascular surgery, angiography, radiotherapy, bronchial artery embolisation, and umbilical artery injection, are disturbances of the blood supply or toxic mechanisms. The ischaemic genesis of spinal cord damage is obvious in the case of vessel ligatures or cross-clamping of the aorta with resulting hypotonic discirculation. In radiomyelopathy as well, the damage to the spinal vessels outweighs the direct neuronal damage. Corresponding to the vascular cause, lesions are more likely to occur at the level of borderlines of blood supply in the middle thoracic cord or in the area of a non-anastomosed great radicular artery in the lumbar spinal cord. Knowledge of the consequences and side effects of medical treatment is imperative. Knowing about the risk of a paraplegic lesion, we need a strict indication for diagnostic and therapeutic interventions. Due to progress in science some of the reasons of iatrogenic paraplegia have become manageable. Especially in radiotherapy, vascular surgery and angiography the risk of neurological complications has been lowered.

Keywords: paraplegia; laminectomy; spondylolesis; angiography; aortic surgery; radiomyelopathy

\section{Introduction}

Paraplegia causes severe and in most cases lasting changes in the patient's life. Paraplegia can not only be linked with a disease or have traumatic causes, but it can also follow medical intervention. This paper describes cases of diagnostic and therapeutic interventions bearing the risk of paraplegia, and shows the pathomechanisms which underlie these lesions. We will discuss protective measures to minimise or eliminate this risk. Can a beginning spinal cord lesion be prevented and a restitution be reached by early recognition?

\section{Methods}

In the Orthopedic University Hospital of Heidelberg (section Orthopedics II, treatment and rehabilitation of paraplegics), 3006 paraplegics were clinically

Correspondence: $\operatorname{Dr} \mathrm{T}$ Bacher, Sporthilfe e.V. Krankenhaus für Sportverletze Hellersen, Paulmannshoher, Strasse 17, 58515 Ludenscheid, Germany

We would like to thank V Paeslack, recently deceased, for his contribution to this paper rehabilitated between 1968 and 1991. In 21 of these patients, a diagnosis of iatrogenic paraplegia was found. The incidence of iatrogenic paraplegia is $0.69 \%$ in this group of patients. The average age of the 14 male and 7 female patients is 34.4 years (neonate -70 years).

The evaluation was done retrospectively on the basis of the available paraplegologic findings at the time of admission and during the course of the treatment in our clinic and on the basis of the medical and surgical reports of the referring hospitals.

\section{Results}

Tables

Figure 1 shows a diagram of the 21 cases of iatrogenic paraplegia, arranged in groups according to the medical treatment performed. The most important data, like the diagnosis before the treatment, the patient's age, date and kind of intervention, are listed in Table 1 by serial numbers. 


\section{Case reports}

Paraplegia after spinal surgery $(\mathrm{n}=8)$

Laminectomy/vertebrotomy $(\mathrm{n}=6)$ A decompressive intervention (laminectomy/hemilaminectomy) was performed in five patients of this group.

Patient 1 showed a spastic paresis of both lower limbs caused by tuberculous spondylitis, which got worse after laminectomy of T4-8 and widening of the spinal canal.

In patient 2 sciatic pain on the right side with a paresis of the right ankle dorsiflexors led to the diagnosis of a spinal arachnoiditis. Some years ago he had a fracture of several distal ribs and the second lumbar vertebra. After laminectomy of T9-12 a complete paraplegia resulted at the neurological level of T10.

Patient 3 showed a paresis of both legs and a spinal ataxia because of extended hyperostosis in an

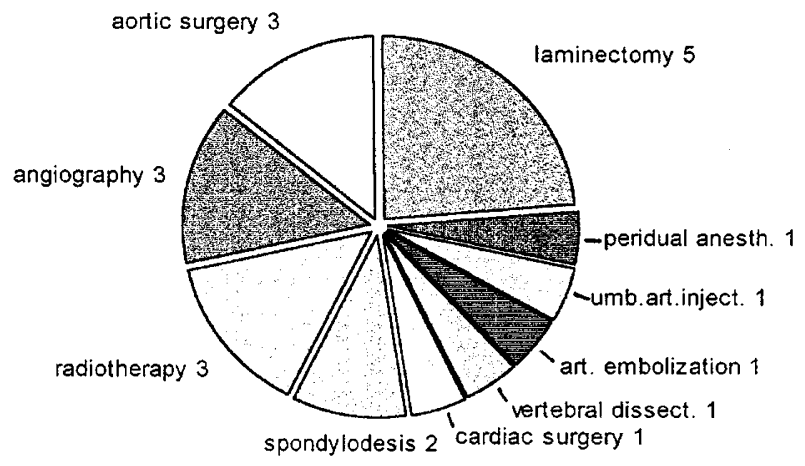

Figure 1 Cases of iatrogenic paraplegia achondroplasia. Laminectomy of T5-9 led to complete paraplegia at the neurological level of T8.

Beginning paraplegia because of a herniated intervertebral disc in segment $\mathrm{T} 10 / 11$ was recognised in patient 4. After laminectomy and removal of the sequester he showed a complete paraplegia at the neurological level of T10.

Patient 5 suffered from sciatic pain in the left leg because of a stenosis of the lateral recess. Exact preoperative neurological status was not available. After hemilaminectomy of the fifth lumbar vertebra and neurolysis of the roots L4, L5 and S1 he showed a cauda equina syndrome with an areflexic bladder.

In patient 6 , who suffered from tuberculous spondylitis with thoracic formation of a gibbus, a vertebrotomy with removal of the focus and blocking of the thoracic vertebral bodies 7-9 with grafts of spongiose and bone chips was performed. The patient did not show any preoperative neurological failures. Postoperatively, he showed a complete paraplegia with neurological level T7.

Cases 1-5 showed a preoperative neurological lesion which became significantly worse immediately after the operation. Table 3 shows the preoperative neurological status and the postoperative neurological level, divided in sensory and motor level completed by the motor score of the Standard Neurological Classification of spinal cord injury. Exact pin prick and light touch scores were not obtainable because they were not documented in the charts.

Spondylodesis at scoliosis $(\mathrm{n}=2)$ One case of polio-scoliosis was instrumented with the Cotrel-

Table 1 Case reports

\begin{tabular}{lcrlrl}
\hline No. & Male/Female & Age & Diagnosis & Date & Treatment \\
\hline 1 & $\mathrm{~m}$ & 20 & Tuberculous spondylitis & 11.07 .68 & Laminectomy T4-8 \\
2 & $\mathrm{~m}$ & 36 & Spinal arachnoiditis & 09.07 .70 & Laminectomy T9-12 \\
3 & $\mathrm{f}$ & 44 & Achondroplasia, spin. stenosis & 04.03 .73 & Laminectomy T5-9 \\
4 & $\mathrm{~m}$ & 49 & Herniated disc T 10/11 & 15.03 .74 & Laminectomy T10 \\
5 & $\mathrm{~m}$ & 66 & Lumbar recessus stenosis & 29.06 .87 & Hemilaminectomy L5 \\
6 & $\mathrm{~m}$ & 28 & Tuberculous spondylitis & 06.06 .69 & Vertebral dissection T7-9 \\
7 & $\mathrm{f}$ & 36 & Polio-scoliosis & 24.03 .88 & CD-spondylodesis T4-S1 \\
8 & $\mathrm{f}$ & 22 & Idiopathic scoliosis & 04.03 .91 & Spine-fix spondylodesis T5-L4 \\
9 & $\mathrm{f}$ & 39 & Hematuresis & 23.01 .70 & Renal artery angiography \\
10 & $\mathrm{~m}$ & 70 & Hypertension & 19.06 .87 & Renal artery angiography \\
11 & $\mathrm{~m}$ & 27 & Vertiginous attack & 12.12 .72 & Carotid angiography \\
12 & $\mathrm{~m}$ & 69 & Hemoptysis & 19.02 .90 & Bronchial artery embolization \\
13 & $\mathrm{~m}$ & 7 & Coarctation of aorta & 16.10 .84 & Dacron-patch plastic \\
14 & $\mathrm{~m}$ & 57 & Arterial occlusive disease & 23.12 .86 & Aorto-femoral bypass \\
15 & $\mathrm{~m}$ & 30 & Aortic aneurysm & 28.02 .73 & Dacron-prosthesis \\
16 & $\mathrm{f}$ & 5 & Fallot's tetralogy & 05.06 .79 & Total correction \\
17 & $\mathrm{f}$ & 39 & Hodgkin's disease & Sept. 69 & Radiotherapy \\
18 & $\mathrm{~m}$ & 15 & Hodgkin's disease & Nov. 69 & Radiotherapy \\
19 & $\mathrm{f}$ & 16 & Hodgkin's disease & Aug. 73 & Radiotherapy \\
20 & $\mathrm{~m}$ & 57 & Abdom. lypmhangioma & 22.05 .89 & Peridural anaesthesia \\
21 & $\mathrm{~m}$ & neo. & Neonatal asphyxia & 26.01 .84 & Umbilical artery injection \\
\hline
\end{tabular}


Dubousset (CD)-system, after ventral osteo-discectomy and halo-traction (case 7). At the parietal vertebra T8 and L2, the initial finding showed a scoliosis angle after Cobb of $128^{\circ}$ thoracal and $130^{\circ}$ lumbar. With halo-traction, an angle of $90^{\circ}$ was reached. After performing the CD-instrumentation, the thoracic value was $51^{\circ}$ and the lumbar value $52^{\circ}$ after Cobb.

In case report 8 , the initial finding showed a rightconvex idiopathic scoliosis of $40^{\circ}$ after Cobb with the parietal vertebra T9. In this case, after a halo-traction, the Spine-Fix-instrumentarium was used from T5 to L4.

The intraoperative wake up test represented the following problems. The test could not be done because of a motoric paralysis after poliomyelitis in patient 7 , and in patient 8 the mobility of one of her legs could not be judged exactly. In case 8 , a rapid regression of the symptoms followed the removal of the instrumentarium. In the other case, the complete paraplegia remained below segment $\mathrm{T} 5$.

Paraplegia after angiography $(\mathrm{n}=3)$ Two patients were paraplegic after a selective renal artery angiography. In patient 9 the contrast medium $(8 \mathrm{ml}$ Angiografin) was unintentionally injected under fluoroscopy into the lumbar artery situated next to the renal artery. In case 10 the paraplegia developed after a small amount of contrast medium had been injected into the lumbar artery, while searching the ostium of the right renal artery. The level of paraplegia was noted at T11 (case 9) and T12 (case 10).

Another patient (case 11) developed a high incomplete tetraplegia in the course of a carotid angiography with Conray 60 with an extended a

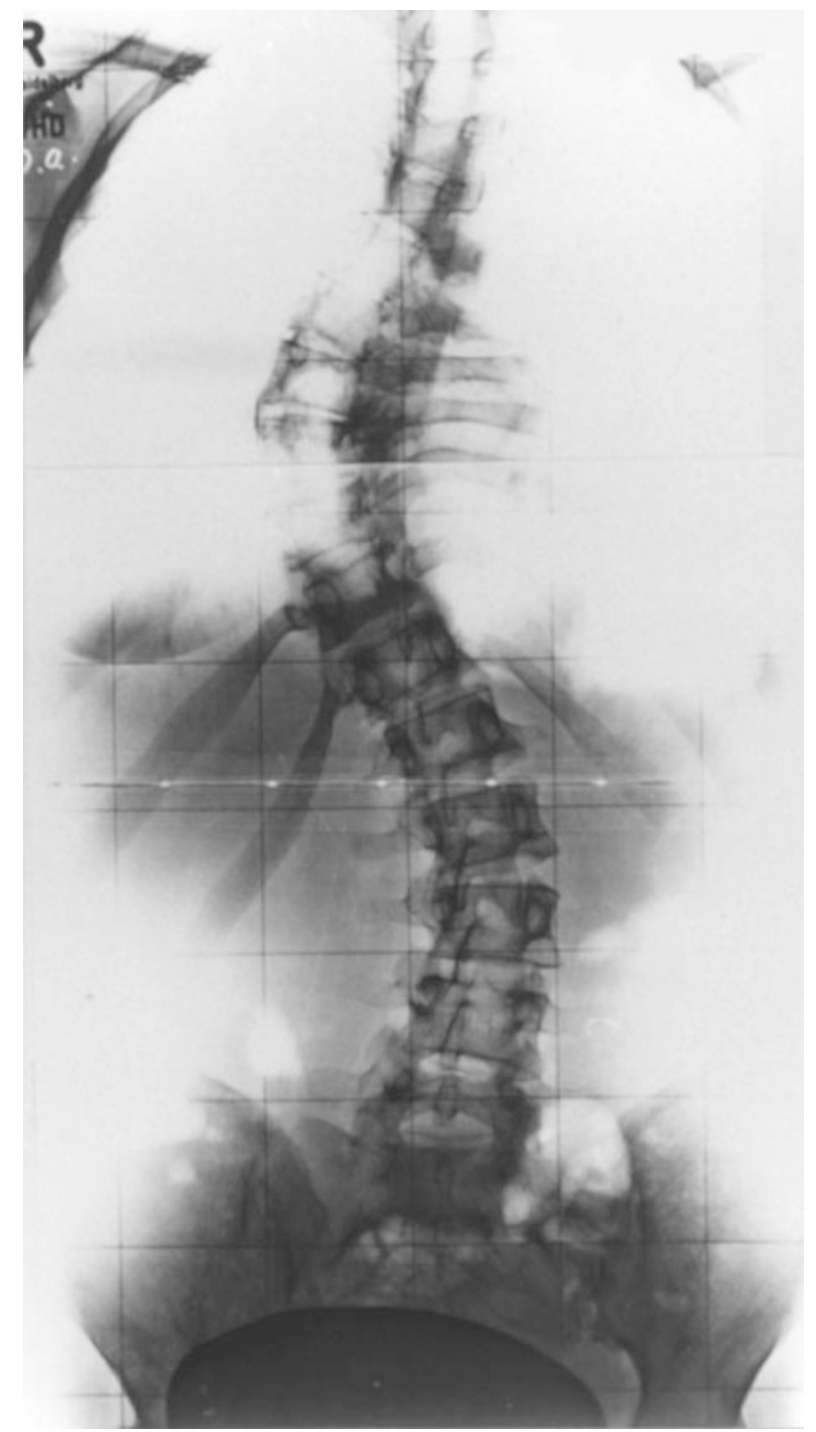

b

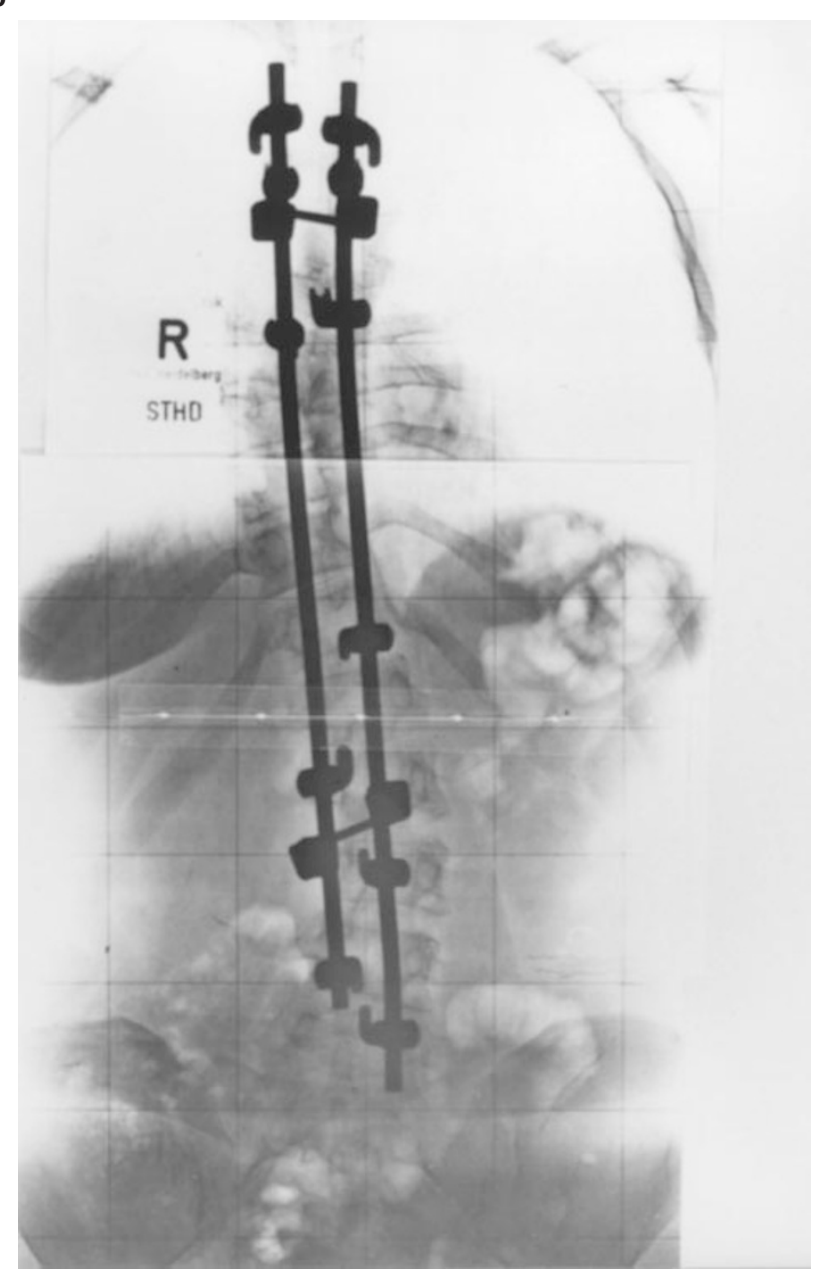

Figure 2 (a) Preoperative radiograph of patient 8. (b) Postoperative radiograph of patient 8 after spondylodesis with the Spinefix-system 
hypoplasia of the vertebral and basilar arteries. A previously conducted survey angiography showed an abnormality of the vertebral artery that should have been further examined.

Paraplegia after bronchial artery embolization $(\mathrm{n}=1)$ In a 69-year-old patient (case 12), who had suffered from hemoptysis for years, two sublobe arteries of the right lung were embolised with $1.5 \mathrm{ml}$ of Ethibloc through a femoral catheter. Postoperatively, an incomplete anterior cord syndrome below segment T8 was diagnosed.

Paraplegia after aortic surgery $(\mathrm{n}=3) \quad$ Three patients underwent aortic surgery. In case 13 a pair of thoracic segmental arteries was ligated at the correction of a coarctation of aorta. After the implementation of an aorto-profundal Dacron-bypass in a patient (case 14) suffering from arterial occlusive disease of the iliac and femoral arteries, an incomplete cross-section below segment T11 was reported. Paraplegic symptoms below T7 complicated the resection and bypass of a suprarenal posttraumatic aortic aneurysm by means of a $24 \mathrm{~mm}$ Dacron-interposition (case 15).

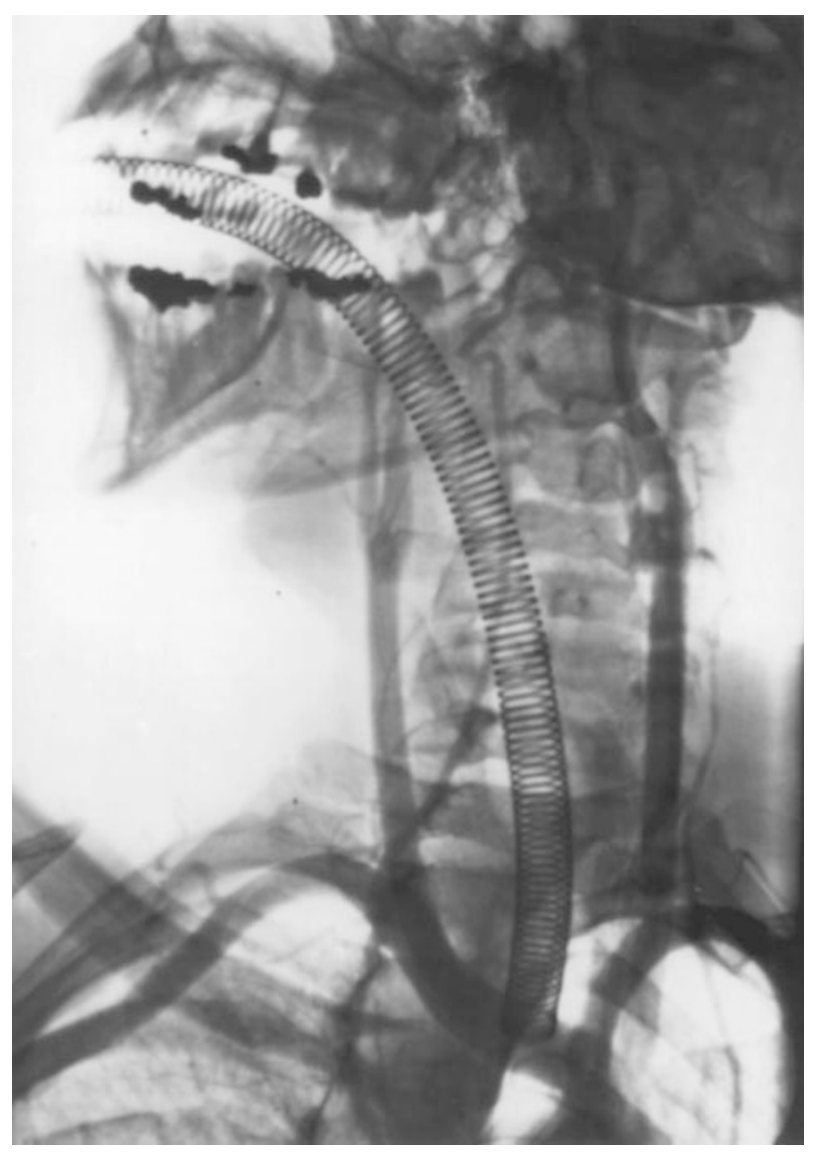

Figure 3 Angiography of aortic arch with carotid and vertebral arteries (case No. 11)
Paraplegia after cardiac surgery $(\mathrm{n}=1) \quad$ On a 5-year old female patient (case 16) a total correction of Fallot's tetralogy was performed under hypothermia and extracorporal circulation. Two hours after the surgery, a cardio-vascular arrest occurred, which could only be controlled by direct cardiac massage after re-thoracotomy. On the first day after the operation, incomplete paraplegia below T3 was diagnosed.

Paraplegia after irradiation for Hodgkin's disease $(\mathrm{n}=3) \quad$ In the $1960 \mathrm{~s}$ and early $70 \mathrm{~s}$, the patients discussed in this paper were treated radiotherapeutically for lymphomatosis granulomatosa. X-ray $(n=1)$ and telecobalt $(n=2)$ irradiation were carried out. In all cases the typical symptoms of a radiation myelopathy $^{2}$ developed, which progressed from a hemilateral, mostly mordant, segmental paresthesia to symptoms similar to those of Brown-Séquard syndrome, and finally to an incomplete para- or tetraplegia (cases 17-19).

Paraplegia after peridural anaesthesia $(\mathrm{n}=1)$ A 57 year-old patient (case 20) suffering from diabetes, developed a skin infection a couple of days after an epidural anaesthesia, which was locally treated. Nine days after the operation, after having suffered from back pain, he showed signs of a transverse lesion below T5, which remained irreversible in spite of an immediate laminectomy and the removal of the epidural abscess.

Lumbosacral plexus lesion after umbilical artery injection $(\mathrm{n}=1)$ A bicarbonate-glucosis buffer solution was injected into the umbilical artery of a neonate (case 21) because of postpartum asphyxia. A flaccid paralysis below segment L2 as well as cutaneous and fat necroses developed in the gluteal area.

\section{Discussion}

In accordance with the cases presented in this paper, Meinecke $^{3}$ reports of transverse lesions after surgical interventions at herniated discs, stenoses of the spinal canal, aortic aneurysms, and after angiography, spinal anaesthesia, and an intraoperative cardiac arrest. Out of 2500 patients of a paraplegia treatment centre, he names 43 cases which indicated iatrogenic causes of the lesions.

In our report we will give a description of the anatomic and physiological particularities of the spinal cord and explain the pathomechanisms of the different case groups.

Pathophysiology and blood supply of the spinal cord Vascular supply The spinal cord is mainly supplied by the great ventral artery which runs in longitudinal direction. It is supplied by the aorta and the vertebral arteries via segmental arteries which are arranged 


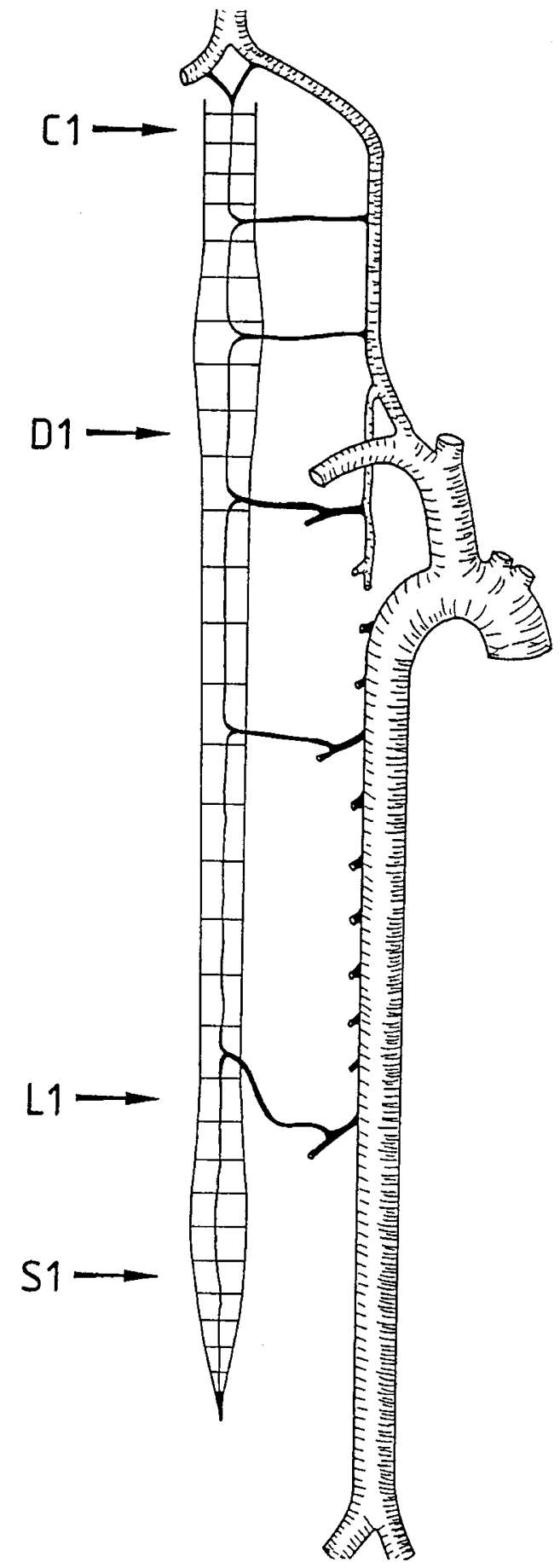

Figure 4 Formation of the anastomotic chain of the anterior spinal artery, modified after Jellinger $\mathrm{K}^{6}$

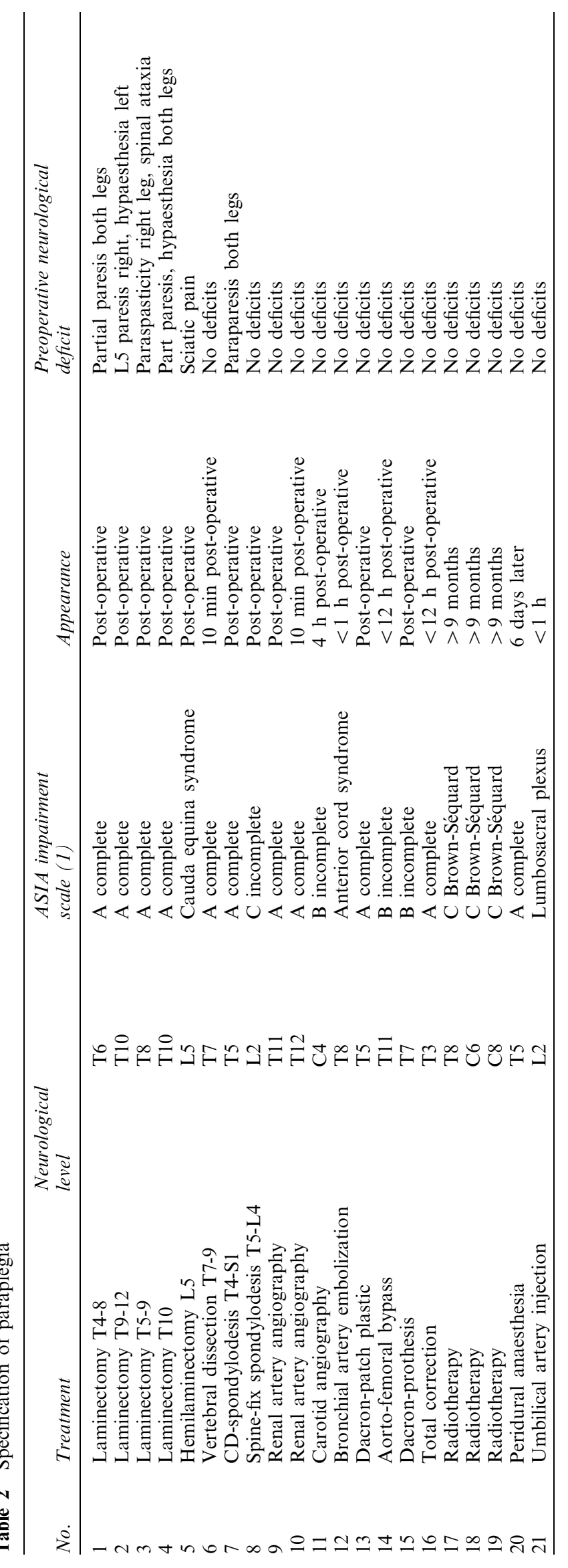


irregularly. The cervical supply is good, whereas the afflux in the middle thoracic section is sparse.

Number and level of the segmental arteries differ individually. The lumbar area is often supplied by one large vessel, the Adamkiewicz artery. This strong artery usually communicates with the anterior spinal artery in the lower area of the thoracic cord from the left side. ${ }^{4}$

Suh and Alexander ${ }^{5}$ reported in 1939 that the anterior spinal artery represents an anastomotic chain of the branches of the anterior radicular arteries, resulting in different diameters. The smallest diameters can be found in the middle thoracic section. Corresponding to the fact that in most cases the lumbar myelon is only supplied from the great radicular artery, the branch of the anterior spinal artery running from the great radicular artery in distal direction always has a significantly larger diameter than the branch running in cranial direction. ${ }^{4}$

Blood flow physiology Due to the special arrangement and the different sizes of the supplying arteries, there are three main flow directions in the anterior spinal artery: (1) from cranial out of the vertebral arteries to distal up to the level of segment T3, (2) from the great radicular artery in cranial direction, (3) from the great radicular artery in caudal direction.

At the level of segment T4, two opposite flow directions converge. This leads to the formation of an area of terminal circulation with an increased risk of underperfusion. A further borderline of the arterial supply can form in the lumbar area if the great radicular artery branches off at a high level, and the lumbar radicular artery branches off at a low level. ${ }^{7}$

\section{Mechanical (direct) damage}

In the group of spinal surgery (laminectomy/vertebrotomy/spondylodesis) and the single description of a peridural abscess, there is an association between the area of treatment and the ensuing level of paraplegia. This becomes particularly clear in the case of decompressing spinal operations (cf. Table 3 ). In these cases the surgical measures were carried out in the immediate proximity of the spinal cord, and therefore a mechanical damage is most likely.

Laminectomy Laminectomy at a herniated thoracic disk, ${ }^{9}$ tuberculous spondylitis, ${ }^{10}$ deformity of the spine, and preoperative neurological symptoms ${ }^{11}$ contribute to an increased rate of complications during and after laminectomy. The general risk of a complication during operations at the lumbar spine was estimated at $9.1 \%$ by Deyo et al ${ }^{12}$ For mere laminectomy, especially in the case of a spinal stenosis, the risk increased to $13.9 \%$, whereas complications arose in $19.0 \%$ of the spondylodeses without laminectomy and in $19.6 \%$ of the spondylodeses with laminectomy. Similar to patient 5 in our group, Valls et $a l^{13}$ reported on a spinal cord

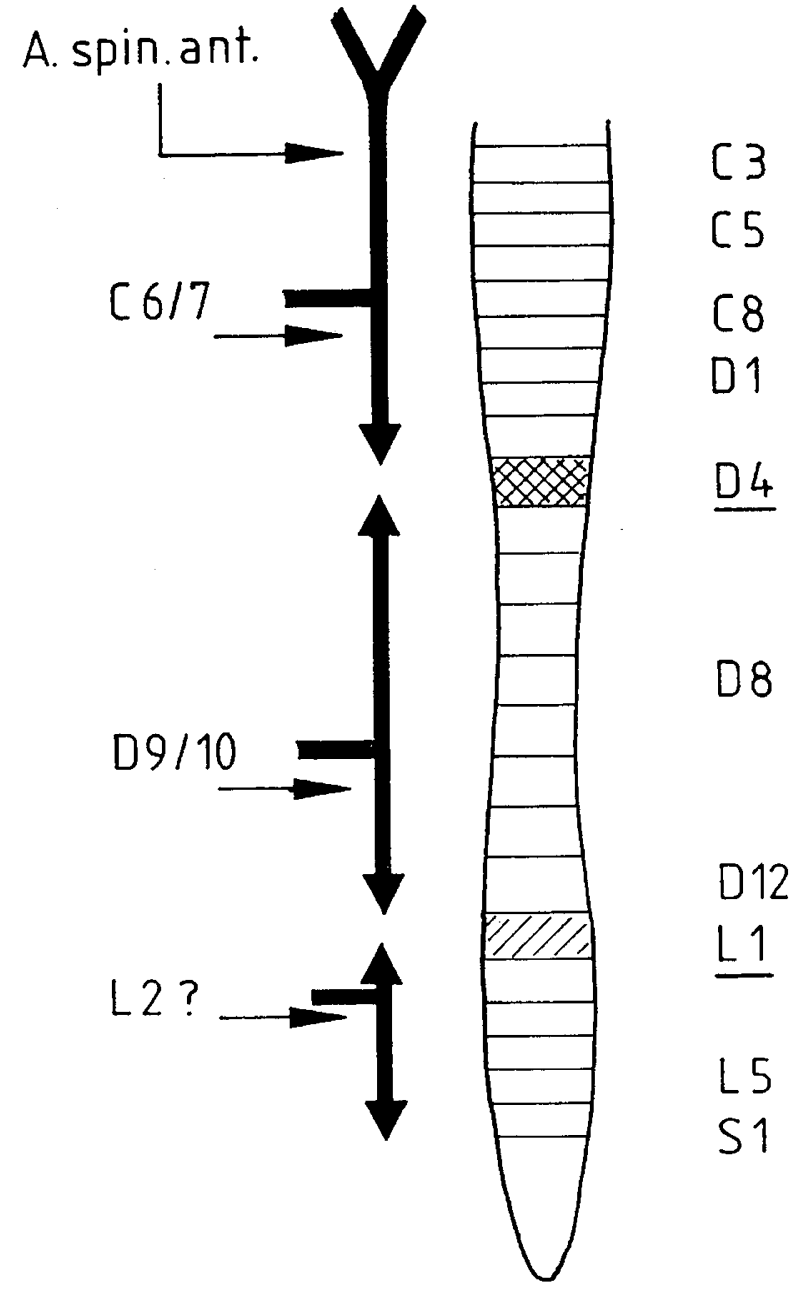

Figure 5 Borderlines of arterial supply in spinal cord, modified after Zülch $\mathrm{KJ}^{8}$

Table 3 Association between level of treatment and level of paraplegia

\begin{tabular}{llcc}
\hline No. & Treatment & $\begin{array}{c}\text { Level of } \\
\text { treatment }\end{array}$ & $\begin{array}{c}\text { Neurological } \\
\text { level }\end{array}$ \\
\hline 1 & Laminectomy & T4-8 & T6 \\
2 & Laminectomy & T9-12 & T10 \\
3 & Laminectomy & T5-9 & T8 \\
4 & Laminectomy & T10 & T10 \\
5 & Hemilaminectomy & L5 & L5 \\
6 & Vertebral dissection & T7 -9 & T7 \\
7 & CD-spondylodesis & T4-S1 & T5 \\
8 & Spine-fix spondylodesis & T5-L4 & L2 \\
\hline
\end{tabular}

compression by a previously asymptomatic arachnoid cyst after routine decompressive lumbar laminectomy for spinal stenosis. Schultz ${ }^{14}$ disapproves of laminectomy as a therapy for lumbar spinal stenosis because of the insufficient functional results and the remaining 
pain. He favours posterolateral decompression. Herniations of a thoracic disk are very rare with an incidence of $1: 100000 .^{15}$ Laminectomy in the case of a thoracic prolapse shows bad results. Ravichandran and Frankel $^{9}$ recommended costotransversectomy instead.

The risk of a neurological lesion after a laminectomy is increased in the case of a spine deformity, particularly in the thoracic area with formation of a gibbus. As early as in 1965, Risko and Novoszel ${ }^{11}$ considered laminectomy to be contraindicated in this deformation, since the spinal cord, which is vulnerable and extended in the area of the gibbus, is exposed to the danger of irreversible damage. In addition, the statics of the already deformed spine is further weakened. Kessler and Leibe ${ }^{16}$ preferred anterolateral decompression to laminectomy because of the greater proximity to the focus and smaller loss of stability.

Osteoarticular tuberculosis takes up the fourth position in the ranks of extrapulmonary tuberculoses. In this context, tuberculous spondylitis is the most common form of localisation of skeletal tuberculosis. ${ }^{16}$ It can be predominantly found in the thoracolumbar transition segments. Non-specific bacterial inflammations occur most commonly in the distal lumbar segments. ${ }^{17,18}$ Tuberculous spondylitis can lead to spontaneous paraplegia. ${ }^{19} 42.5 \%$ of patients with cervical tuberculous spondylitis showed spinal cord compression. $^{20}$

The surgical standard for tuberculous spondylitis is decompression with removal of the focus, ventral reconstructive surgery and postoperative fixation combined with further antibiotic therapy. ${ }^{17,21,23}$ In addition it is possible to carry out a dorsal spondylodesis with instrumentation, which offers the advantage of an early mobilisation as opposed to the long postoperative rest in a plasterbed and/or a corset after ventral non-instrumented bone-chip blocking. ${ }^{24}$ According to Krödel and Stürz ${ }^{17}$ there is an exceptional indication for dorsal decompression through laminectomy in the case of acute symptoms of transverse lesion and a bad general condition of the patient.

Scoliosis Performing a spondylodesis, in the case of scoliosis, degenerative or traumatic instability, there is a danger of mechanical damage of the spinal cord through implants or tractional and shearing forces. In the course of the correction of a scoliosis or kyphosis, disturbances of the vascularisation of the anterior spinal artery are to be discussed. In the case of standardised experimental traumas at the spinal cord, alterations of the spinal perfusion and the oxygen saturation or the oxygen partial pressure in the tissue could be detected. ${ }^{25-27}$ Alterations of the perfusion parameters caused by major tractional and shearing forces can be expected.

The incidence of paraplegia after surgical scoliosis therapy is estimated at less than $1 \%$, in several case studies. Incidence rates differing only slightly between $0.12 \%$ and $0.72 \%$ are mentioned with the various techniques. ${ }^{28-30}$ Faciszewski et $a l^{31}$ found an incidence of $0.2 \%$ for a complicating paraplegia in a review of 1223 thoracic and lumbar anterior spinal fusions.

Halo-traction involves the risk of a transverse lesion as well. ${ }^{28}$ Wilkins and McEwen ${ }^{32}$ detected in six out of 70 patients with halo-traction a lesion of a cranial nerve, which was fully reversible after the reduction of the tractional force. The abducent nerve was often affected. A correlation between the force applied and the neuroparalysis could not be proved.

Paralytic scoliosis did not show an increased operative risk of paraplegia compared to idiopathic scoliosis, which was proved by Leong et al ${ }^{33}$ in 110 operated paralytic scolioses without complicating paraplegia. A possibility to recognise neurological damage during the operation is the intraoperative awakening test. ${ }^{34}$ The intraoperative monitoring of somatosensory evoked potentials is considered more and more important. Alterations of the signal or loss of signal indicate a damage of the spinal cord. The causes, such as a ligature of an artery, an excessive correction of scoliosis, misplaced lamina retractors, transpedicular screws or a dorsally dislocated intervertebral spongiosa graft can be found and corrected. ${ }^{35-37}$ Good prognosis for a regression of the paralysis is achieved by reduction of the traction or quick removal of the instrumentarium. $^{29}$

Peridural anaesthesia The epidural abscess is only a part of the possible complications arising after peridural anaesthesia. Hematoma, unintentional dural puncture, massive subarachnoid injection and convulsions are more common. ${ }^{38} \mathrm{~A}$ delayed paraplegia caused by a subdural hematoma 8 days after spinal anaesthesia was reported by Pryle et $a l^{39}$ in a patient with perioperative intermittent low dose aspirin therapy. Because of a subdural hematoma after

Table 4 Indications for surgery with tuberculous spondylitis ${ }^{16-18,21,22}$

\begin{tabular}{ll}
\hline Absolute & Relative \\
\hline Spinal compression (epid. abscess, sequester) & Prolonged illness \\
Acute neurological symptoms & Increasing kyphosis \\
Proceeding neurological symptoms & Huge destruction with loss of substance \\
Wedge-shaped deformity with thoracic hump & Continuous severe pain \\
\hline
\end{tabular}


attempted spinal anaesthesia, a 72 year old woman suffered from paraplegia below L3 $12 \mathrm{~h}$ after surgery. Neurosurgical decompression could not lead to recovery. ${ }^{40}$ Due to frequent delay between diagnosis and therapy of an epidural abscess there is a high mortality and a large number of patients with lasting damages. In $64 \%$ of the patients, staphylococcus aureus could be detected in the smear, and $60 \%$ of the patients showed a weakened immunity. ${ }^{41}$

In a review of literature on epi- and subdural hematomas in spinal or epidural anaesthesia Schmidt ${ }^{42}$ described the frequent peri- or postoperative administration of drugs influencing blood coagulation. Although it is called an extremely rare complication, there is a relatively good prognosis if operative decompression is performed within $8 \mathrm{~h}$ after onset of paraplegia. The incidence of paraplegia as complication of peridural anaesthesia was estimated to be $0.01 \%$ by Usubiga et $a .^{43}$

\section{Disturbance of vascularisation (indirect damage)}

Damage of the spinal cord due to disturbances of the vascular supply can be caused by temporary occlusion, lasting interruption or embolic occlusion of the supplying system. As a result of the peculiarities of the spinal blood supply presented in 4.1, the interruption of a segmental or radicular artery can already lead to a severe ischaemia of the spinal cord. Disturbance of the perfusion can also be caused by low blood pressure. The cases described in the following show a coincidence between the development of paraplegia and the disturbance of vascularisation or circulation. In the case of paraplegia after angiography an essential neurotoxic cause is to be discussed.

Angiography Until 1974, medullary incidents with paraplegia after an aortography or angiography were discussed in more than 100 cases. ${ }^{44}$ The introduction of non-ionic low-molecular contrast media at the beginning of the 1980s reduced allergic reactions and neurotoxicity. In various case studies of brachiocephalic angiography, rates of neurologic complications up to $10 \%$ with the use of non-ionic contrast media and $12.2 \%$ with ionic contrast media were described. ${ }^{45}$ For more than 700 angiographies of the aortic arch and of brachiocephalic vessels, Gross-Fengels et $a l^{45}$ calculated a complication rate of $0.7 \%$ for persisting neurological deficits. A rather more frequent cause of neurological complications at catheter angiographies seems to be catheter-embolism, further causes are summed up in Table 5. Even in a coronary angiogram the complicating ischemic paraplegia below L1 was described by Otom et al. ${ }^{46}$

In the case reports mentioned in this paper, a toxic damage at the localisation of the selective catheter in the great radicular artery is probable in one case (case 9). In view of the low neurotoxicity of today's contrast media, the loosening of a thromboembolic plaque off the catheter tip or the atherosclerotic lumen of the
Table 5 Causes of neurological complications at angiography

Catheter embolism (increased platelet aggregation)

Loosening of thromboembolic plaques by manipulation

Allergic reaction

Quantity of contrast medium

Kind of contrast medium (ionic, non-ionic)

Duration of examination $(>80 \mathrm{~min})$

Localisation of vessel puncture

vessel is to be discussed in the second patient (case 10). In the third patient, apart from hypoplasia of the vertebral arteries, a combination of underperfusion, neurotoxicity and probably an allergic shock reaction to the plasma expander caused the neurological complications. This could explain the fact that the paraplegia did not occur until $4 \mathrm{~h}$ after the application of the contrast medium.

Bronchial artery embolisation The embolisation of bronchial arteries as a therapy for chronic hemoptyses, especially in patients with an increased operative risk, is a method described repeatedly in the literature. ${ }^{47-49}$ Spreading of sclerosing material with thrombosis of the anterior spinal artery is a wellknown risk. In two cases, Helenon et al ${ }^{48}$ described monitoring of the anterior spinal artery via connections between the pathological bronchial artery and the supplying intercostal artery during a selective angiography performed before the sclerosing. Elsewhere, the complicating ischaemic colitis after bronchial artery embolisation is described. ${ }^{50}$

Aortic surgery Aortic aneurysm Especially in the surgery of aortic aneurysms paraplegia is a feared complication. In 1959 Debakey et al $^{51}$ published an incidence of paraplegia of 5.5\% after surgery for thoracic aortic aneurysms. In a survey of 1070 reconstructive procedures of the infrarenal aorta Tonz et $a l^{52}$ reported an incidence of paraplegia of $0.19 \%$. Comparable incidences were reported by Gloviczki et $a l^{53}$ in 1991 for operations on the abdominal aorta $(0.3 \%)$. For elective surgery the incidence for ischaemic spinal cord injury was $0.1 \%$, whereas the incidence for emergency aneurysm repair was $1.4 \%$ and for repair of occlusive disease $0.3 \%$. In aortic surgery, paraplegia results from a ligature of segmental arteries and intraoperative aortic occlusion.

Aneurysm types I-III after Crawford, which correspond to a localisation between the descending thoracic part and the thoraco-lumbar transition area, are particularly at risk for paraplegia. For type II, a rate of paraplegia as high as $29 \%$ is given in the literature. ${ }^{54}$ With regard to the time of aortic occlusion, Weimann et $a l^{55}$ described 13 posttraumatic aneurysms, which were operated with an average time of occlusion of $38 \mathrm{~min}$ without neurological complications. Sandmann et $a l^{54}$ generally consider 
an interruption of the perfusion of the segmentary arteries supplying the spinal cord of up to $40 \mathrm{~min}$ quite safe with regard to the risk of paraplegia.

In addition to measures which help to minimise the risk, such as extracorporal circulation with deep hypothermia, ${ }^{56}$ doses of cytoprotective substances ${ }^{54}$ or measuring and lowering of the cerebrospinal pressure, ${ }^{57}$ special attention was directed to the reattachment of segmentary arteries to the vascular replacement.

Due to the particular physiology and the special relevance of the great radicular artery for the supply of the lumbar cord, the spinal artery was angiographically pictured before the operation. The corresponding segmental artery was inspected or refixed in the course of the operation. The postoperative rate of paraplegia could thus be lowered. ${ }^{58-60}$

At an extended aneurysm, Miyagi et $a l^{59}$ recommended the reimplantation of as many segmental arteries as possible under extracorporal circulation and segmental occlusion of the arteries (clamp and repair). Special attention was put on segmental sequential repair to minimise the duration of ischaemia to any given vascular bed by Frank et al. ${ }^{61}$

Sandmann et $a l,{ }^{44}$ however, criticised that none of the previously applied methods was able to give intraoperative information about the situation of the spinal cord. Therefore they monitored spinally evoked potentials during the operation, which showed three reaction types to aortic occlusion according to the degrees of collateral supply. A high risk of paraplegia was ascribed to patients who showed a loss of spinally evoked potential 8-15 min after the occlusion. By means of intraoperative spinal neuromonitoring it was possible to immediately judge the effect of the reinsertion of segmental arteries and to connect further segmental arteries to the interposition if necessary. The authors reported a lowering of the paraplegia rate from $11 \%$ to $2 \%$ by this method combined with the medication of prostaglandin $E_{1}$ to prevent ischaemia.

Coarctation of aorta At an aortic stenosis the danger of a spinal ischaemia after the occlusion of the aorta appears to be smaller, since in the course of the illness an extensive collateral circulation via the anterior spinal artery has developed. The incidence of paraplegia in 5492 operations for coarctaction in Great Britain was $0.3 \% .^{62}$ In this case, intraoperative hypotony represents a problem. Distal to the stenosis, which means in the lumbar spinal cord as well, the blood pressure is up to $30 \%$ lower than the proximally registered values. ${ }^{6}$ Therefore Wada et $a l^{57}$ recommended intraoperative measuring of the blood pressure in the distal aorta and obtaining the pressure in the cerebrospinal liquid. In surgery for coarctation as well, intraoperative neuromonitoring is a very useful method, as required by Keen in $1987^{62}$ in combination with electromanometric display of the aortic blood pressure in all patients.
Cardiac surgery Pasternak et al $^{63}$ reported the danger of neurological lesions after intraoperative or postoperative decrease in blood pressure. Taylor et al ${ }^{64}$ described paraplegia caused by postoperative hypotony. The monitoring of the spinal cord with evoked potentials proved the relationship to the postoperative hypotonic phase. Marini and Cunningham ${ }^{65}$ called paraplegia an unpredictable complication of multifactorial origin in aortic and cardiac surgery. Postoperative hypotension is the reason for most of the cases with delayed paraplegia, which have been reported to occur from 1-21 days after surgery. Neuronecroses, particularly in the anterior horn of the spinal cord, were found in a histological examination of the spinal cord of children, who were resuscitated after a cardiovascular arrest but then died. ${ }^{66}$ Rodewald et $a l^{67}$ mentioned effects of extracorporal circulation and hypothermia on the cerebral autoregulation and microembolisms as main causes of neurological complications in cardiac surgery. Kindt $^{68}$ described the corresponding mechanism of autoregulation for the spinal vessels. Judging from the level of paraplegia in the area of terminal circulation, a hypotonic-ischaemic myelomalacia is probable in the case at hand.

Radiotherapy A distinction is made between 'acute transitory radiation myelopathy' and 'chronic progressive radiation myelopathy'. ${ }^{69}$ The first is reversible, the second shows a latency period of several months. The reason for this are alterations of the vessels such as obliterating endangiitis or perivascular sclerosis or hyalinosis. A lesion of the vessels in the area of terminal circulation is considered the cause of the relatively frequent occurrence of thoracic lesion levels at cervico-thoracic irradiation. If very high radiation doses are applied, damages of nerve cells can be detected after a short time., 20,71

In the 1950's and 60's every stage of Hodgkin's disease was treated radiotherapeutically. In the clinical stage (CS) I/II it was possible to achieve good results, the results in CS III/IV were not satisfactory. In consequence, primary chemotherapy had been developed. Today patterns with a mantle field or extended mantle field are used according to further subclassifications. In the period of time that is covered by this report, a large number of involved field irradiations were run. The results of low-dose primary chemotherapy with local irradiation are currently being examined. ${ }^{72}$

Judging the spinal dose level involves difficulties, since several factors play a role. The field and area of irradiation, fractionation, duration of treatment, and the total dose have to be considered. At the present time, a spinal dose of more than 45-50 Gray (Gy) is considered an unacceptable risk. The difficulty involved in establishing an exact minimum dose can be seen in a case study by Dunst et $a l^{73}$ A spinal dose of $45 \mathrm{~Gy}$ at a conventional fractionation with individual doses of no more than 2 Gy should provide 
sufficient protection against radiomyelitis. In the case study, a radiomyelitis occurred within a latency of 6 months after a spinal maximum dose of $45.8 \mathrm{~Gy}$. Hyperfractionated irradiation, what means an irradiation twice a day with $1.8 \mathrm{~Gy}$ each, is considered the reason for this. The short fractional intervals seem to overtax the repair mechanisms taking place in the spinal cord.

Glanzmann and Lütolf ${ }^{72}$ give a maximum spinal dose of 38 Gy when only radiotherapy is applied, and $36 \mathrm{~Gy}$ when additional chemotherapy is applied. If all these regulations are followed, radiomyelopathy involves a rather low risk. As a complication of radiotherapy it numerically ranks behind solid secondary tumors and Non-Hodgkin's lymphomas.

Compared to the early 1960's, progress in irradiation techniques, the establishment of a therapeutical plan, and the sensitivity of the fractionation lowered the risk of serious alterations of surrounding tissue.

Umbilical artery injection Until 1962 more than 40 lesions of the lumbrosacral plexus after erroneous injection into the umbilical artery had been described. ${ }^{74}$ The injection of a buffer solution into one of the umbilical arteries of a new-born child can lead to lesions of the lumbosacral plexus, as in new-born children the solution reaches the inferial gluteal artery via the internal iliac artery. A large part of the lumbosacral plexus is supplied by the inferior gluteal artery. Apart from a lesion of nerves, cutaneous and fat necroses in the gluteal area and the lower limbs are among the typical consequences. In 1993 again two cases of neonatal flaccid paraplegia after umbilical artery catheterisation were reported by Munoz et al. ${ }^{75}$

\section{Conclusion}

Some of the reasons of iatrogenic paraplegia discussed in this paper have become avoidable, due to progress in science. Particularly in radiotherapy and in angiography the risk of neurological complications has been lowered. The risk of paraplegia in vascular surgery can be minimised by segmentary occlusion of small sections of the aorta, reattachment of ligatured segmental arteries to the interposition and spinal neuromonitoring.

In vascular and in spinal surgery, intraoperative monitoring of spinally and cortically evoked potentials has attained significance for the early recognition of damages to the spinal cord. Thus it is possible to intervene in the reversible phase of spinal cord damage. The knowledge of possible paraplegic complications is necessary in surgical or diagnostic procedures, even in procedures distant from the spinal cord. Although paraplegic complications have a very low incidence they involve severe consequences. Therefore paraplegic complications should be a part of the operative permit in elective surgery and diagnostic or therapeutic procedures named in this report. The necessity of the procedure has to be closely proved.

\section{References}

1 Maynard FM et al. International standards for neurological and functional classification of spinal cord injury. Spinal Cord 1997; 35: $266-274$

2 Gänshirt H. Strahlenmyelopathie. Nervenarzt 1975; 46: $562-$ 568.

3 Meinecke FW. Rückenmarkschäden im Gefolge von Diagnostik und Therapie. Unfallchirurg 1988; 91: 270-277.

4 Domisse GF. The blood supply of the spinal cord. J Bone Joint Surg (Br) 1974; 56: $225-235$.

5 Suh TH, Alexander L. Vascular system of the human spinal cord. Arch Neurol Psychiatry 1939; 41: 659-677.

6 Jellinger K. Durchblutungsstörungen des Rückenmarks. Wien Klin Wochenschr 1967; 79: 41-51.

7 Bartsch W. Die Pathogenese und Klinik der spinalen Durchblutungsstörungen. In: Olivecrona H, Tönnis D, Krenkel (ed). Handbuch der Neurochirurgie Bd. 7, Teil 2. Springer: Berlin Heidelberg New York 1972; pp 607-675.

8 Zülch KJ. Mangeldurchblutung an der Grenze zweier Grfäßgebiete als Ursache bisher ungeklärte Rückenmarkschäden. Dtsch Z Nervenheilkd 1954; 172: 81 - 101.

9 Ravichandran G, Frankel HL. Paraplegia due to intervertebral disc lesions: A review of 57 operated cases. Paraplegia 1981; 19: $133-139$.

10 Moula T, Fowles JV, Kassab MT, Sliman N. Pott's Paraplegia. A clinical review of operative and conservative treatment 63 adults and children. Int Orthop 1981; 5: $23-29$.

11 Risko T, Novoszel T. Angaben über Kontraindikationen der Laminektomie bei Patienten mit Wirbelsäulendeformität. Z Orthop 1965; 16: $425-430$.

12 Deyo RA et al. Morbidity and mortality in association with operations on the lumbar spine. J Bone Joint Surg (A) 1992; 74: $536-543$.

13 Valls PL, Naul LG, Kanter SL. Paraplegia after a routine lumbar laminectomy: report of a rare complication and successful management. Neurosurgery 1990; 257: 638-640.

14 Schulitz KP. Das Risiko der Instabilität nach Dekompressionsoperationen der lumbalen Instabilität. Z Orthop 1995; 133: $236-$ 241.

15 Carson J, Gumpert J, Jefferson A. Diagnosis and treatment of thoracic intervertebral disc protrusions. J Neurol Neurosurg Psychiatry 1971 34: 68-77.

16 Kessler P, Leibe H. Die Behandlung der Spondylitis tuberculosa unter besonderer Berücksichtigung der Indikation zur operativen Herdausräumung. Beitr Orthop Traumatol 1982; 29: 188-195.

17 Krödel A, Stürz H. Differentzierte operative und konservative Therapie der Spondylitis und Spondylodiscitis. Z Orthop 1989; 127: $587-596$

18 Wen-Jer Chen, Chih-Hwa Chen, Chun-Hsiung Shih. Surgical treatment of tuberculous spondylitis. Acta Orthop Scand 1995; 66: $137-142$

19 Kadah H, Naughton B. Pott's paraplegia: a complication of tuberculous spondylitis. J Am Geriatr Soc 1992; 40: 710-712.

20 Hsu LC, Leong JC. Tuberculosis of the lower cervical spine (C2 to C7). A report on 40 cases. J Bone Joint Surg ( Br) 1984; 66: 1 5 .

21 Brussatis F, Blümlein H, Wunderlich T. Ergebnisse nach Ausräumung und ventraler Fusion bei Spondyliten. Z Orthop 1983; 121: $458-459$

22 Härle A. Spondylitis. In: Bauer M, Kerschbaumer F, Poisel S (ed). Orthopädische Operationslehre, Band I Wirbelsäule. Thieme: Stuttgart, New York 1991; pp 377-390.

23 Heine J, Immenkamp M, Matthias HH. Ergebnisse der operativen Behandlung der Spondylitis tuberculosa. Z Orthop 1983; 121: 457

24 Meurer A, Eysel P, Heine J. Ergebnisse der operativen Behandlung der Spondylitis tuberculosa. Z Orthop 1995; 133: $227-235$.

25 Ducker TB, Perot PL. Spinal cord oxygen and blood flow in trauma. Surg Forum 1971; 22: $413-415$. 
26 Kelly DL, Lassiter KR, Calogero JA, Alexander E. Effects of local hypothermia and tissue oxygen studies in experimental paraplegia. J Neurosurg 1970; 33: 554-563.

27 Locke GE, Yashon D, Feldman RA, Hunt WE. Ischemia in primate spinal cord injury. J Neurosurg 1971; 34: 614-617.

28 Swank S et al. Surgical treatment of adult scoliosis. A review of 222 cases. J Bone Joint Surg (Am) 1981; 63: 268-287.

29 McEwen GD, Bunnell WP, Sriram K. Acute neurological complications in the treatment of scoliosis. J Bone Joint Surg ( Am) 1975; 57: 404-408.

30 Lowe TG. Morbidity and mortality report. American Scoliosis Research Society 1987.

31 Faciszewski $\mathrm{T}$ et al. The surgical and medical perioperative complications of the anterior spinal fusion surgery in the thoracic and lumbar spine in adults. A review of 1223 procedures. Spine 1995; 20: $1592-1599$.

32 Wilkins C, McEwen GD. Cranial nerve injury from halo traction. Clin Orthop 1977; 126: $106-110$.

33 Leon JCY et al. Surgical treatment of scoliosis following poliomyelitis. J Bone Joint Surg (Am) 1981; 63: 726-740.

34 Hall JE, Levine CR, Sudhir KG. Intraoperative awakening to monitor spinal cord function during Harrington instrumentation and spine fusion. Description of procedure and report of three cases. J Bone Joint Surg (Am) 1978; 60: $533-536$

35 Apel DM et al. Avoiding paraplegia during spinal surgery. The role of somatosensory evoked potential monitoring with temporary occlusion of segmental spinal arteries. Spine 1991; 16: $365-370$.

36 Michel F et al. Les complications neurologiques de la chirurgie des deformation des rachis. Rev Chir Orthop Reparatrice Appar Mot 1992; 78: $90-100$.

37 Tabaraud $\mathrm{F}$ et al. Monitoring of the motor pathway during spinal surgery. Spine 1993; 18: 546-550.

38 Pallot M, Visseaux H, Botmans C, Pire JC. Epidemiologie des complications de l'analgesie peridurale obstetricale. Cah Anaesthesiol 1994; 42: 229 - 233.

39 Pyrle BJ, Carter JA, Cadoux-Hudson T. Delayed paraplegia following spinal anaesthesia. Spinal subdural haematoma following dural puncture with a $25 \mathrm{G}$ pencil point needle at T12-L1 in a patient taking aspirin. Anaesthesia 1996; 51: 263-265.

40 Likar $\mathrm{R}$ et al. Akutes spinales subdurales Hämatom nach versuchter Spinalanästhesie. Anaesthesist 1996; 45: 66-69.

41 Redekop GJ, Del Maestro RF. Diagnosis and management of spinal epidural abscess. Can J Neurol Sci 1992; 19: 180-187.

42 Schmidt A, Nolte H. Subdurale und epidurale Hämatome nach Periduralanästhesie. Eine Literaturübersicht. Anaesthesist 1992; 41: $276-284$.

43 Usubiga JE. Neurological complications following epidural anaesthesia. Int Anaesthesiol Clin 1975; 13: $151-153$.

44 Broy H. Die spontane Darstellung der A. radicularis magna in abdominellen Aortogramm. Fortschr Geb Roentgenstr 1974; 120: $550-560$.

45 Gross-Fengels W et al. Komplikationen brachiocephaler Katheterangiographien bei Verwendung eines nicht-ionischen Kontrastmittels. Radiologe 1987; 27: $83-88$.

46 Otom A, Hourani F, Hatter E. Ischaemic spinal cord injury following a coronary angiogram: a case report. Spinal Cord 1996; 34: $308-310$.

47 Barret $\mathrm{F}$ et al. Traitement en urgence des hemoptysies graves par embolisation des arteres systemiques. Presse Med 1983; 12: 625 629.

48 Helenon $\mathrm{CH}$ et al. Le traitement des haemoptysies par embolisation des arteres systemiques. J Radiol Electrol Med Nucl 1976; 57: $487-497$.

49 King AD, Cumberland DC, Brennan SR. Management of severe haemoptysis by bronchial artery embolisation in a patient with cystic fibrosis. Thorax 1989; 44: 523 - 524

50 Lemoigne F, Rampal P, Petersen R. Colite ischemique fatale apres embolisation arterielle bronchique. Presse Med 1983; 12: $2056-2057$

51 Debakey ME, Cooley DA, Crawford ES, Morris GC. Aneurysms of the thoracic aorta: analysis of 179 patients treated by resection. J Thorac Cardiovasc Surg 1959; 36: 393-420.
52 Tonz M et al. Die Paraplegie, eine katastrophale Komplikation bei der infrarenalen Aortenchirurgie. Helvetica Chirurgica Acta 1993; 60: $177-181$.

53 Gloviczki $\mathrm{P}$ et al. Ischemic injury to the spinal cord or lumbosacral plexus after aorto-iliac reconstruction. Am J Surg 1991; 162: $131-163$

54 Sandmann W et al. Chirurgische Behandlung des thoracoabdominalen Aortenaneurysmas Chirurg 1995; 66: $845-856$.

55 Weimann $\mathrm{S}$ et al. Graft replacement of post-traumatic thoracic aortic aneurysm: results without bypass or shunting. Eur J Vasc Surg 1992; 6: $381-385$.

56 Guilmet D et al. Chirurgie des aneurysmes thoraciques et thoraco-abdominaux interessant l'artere d'Adamkiewicz. Interet de l'hypothermie profonde. Nouv Presse Med 1981; 10: 3303 3306.

57 Wada $\mathrm{T}$ et al. Reconstructive surgery in 59-year-old patient with coarctaction of aorta under the monitoring of somatosensory evoked potential and spinal cord perfusion pressure. Nippon Kyobu Geka Gakkai Zasshi 1992; 40: $134-140$.

58 Fereshetian A et al. Digital substraction spinal cord angiography in patients undergoing thoracic aneurysm surgery. Cardiovasc Intervent Radiol 1989; 12: 7 -9.

59 Miyagi $\mathrm{K}$ et al. Angiographic evaluation of reconstructed spinal arteries in thoracic aortic aneurysm surgery. Nippon Kyobu Geka Gakkai Zasshi 1993; 41: 2054-2058.

60 Williams GM et al. Angiographic localization of spinal cord blood supply and its relationship to postoperative paraplegia. $J$ Vasc Surg 1991; 13: $23-33$.

61 Frank SM et al. Moderate hypothermia, with partial bypass and segmental sequential repair for thoracoabdominal aortic aneurysm. J Vasc Surg 1994; 19: 687-697.

62 Keen G. Spinal cord damage and operations for coarctation of the aorta: aetiology, practice and prospects. Thorax 1987; 42: $11-18$

63 Pasternak BM, Boyd DP, Ellis FH. Spinal cord injuries after procedures on the aorta. Surg Gynecol Obstet 1972; 135: 29-34.

64 Taylor BA et al. Delayed postoperative paraplegia with hypotension in adult revision scoliosis surgery. Spine 1994; 19: $470-474$

65 Marini CP, Cunningham JN. Issues surrounding spinal cord protection. Adv Card Surg 1993; 4: 89-107.

66 Gilles FH, Nag D. Vulnerability of human spinal cord in transient cardiac arrest. Neurology 1971; 21: 833-839.

67 Rodewald $\mathrm{G}$ et al. Zentralnervöse Risikofaktoren in der Herzchirurgie. Z Kardiol 1990; 79: 13-21.

68 Kindt GW. Autoregulation of spinal cord blood flow. Eur Neurol 1972; 6: $19-23$

69 DeScisciolo $\mathrm{G}$ et al. Long-term nervous sytem damage from radiation of the spinal cord: an electrophysiological study. $J$ Neurol 1991; 238: 9-15.

70 Pallis CA, Louis S, Morgan RL. Radiation myelopathy. Brain 1961; 84: $460-479$.

71 Rivett JD. Paraplegia due to radiation myelitis following the treatment of carcinoma of the bronchus by radiotherapy. Paraplegia 1971; 9: 65-72

72 Glanzmann C, Lütolf UM. Fragen und Aspekte zur Radiotherapie bei erwachsenen Patienten mit lokalisierten subdiaphragmalen Stadien (CS I/II) eines Morbus Hodgkin. Strahlenther Onkol 1993; 169: $449-458$ and 570-583.

73 Dunst J, Dunst U, Wittmoser W. Radiogene Myelitis nach akzelerierter Radiotherapie. Strahlenther Onkol 1993; 169: $543-$ 544.

74 San Agustin M, Nitowsky HM, Borden JN. Neonatal sciatic palsy after umbilical vessel injection. J Pediatr 1962; 60: $408-$ 413.

75 Munoz ME, Roche C, Escriba R, Martinez-Bermejo A, PascualCastroviejo I. Flaccid paraplegia as complication of umbilical artery catheterization. Pediatr Neurol 1993; 9: 401-403. 